\title{
BEHAVIORAL ANTICIPATION IN AGENT SIMULATION
}

\author{
Tuncer I. Ören \\ M\&SNet: Ottawa Center of the MISS \\ School of Information Technology and Engineering \\ (SITE), University of Ottawa \\ Ottawa, ON, K1N 6N5 Canada
}

\begin{abstract}
In this article, the following is done: (1) a systematic and comprehensive classification of input is given and the relevance of perception as an important type of input in intelligent systems is pointed out, (2) a categorization of perception is given and anticipation is presented as a type of perception, (3) the inclusion of anticipation in simulation studies is clarified and other aspects of perceptions in simulation studies especially in conflict situations are elaborated.
\end{abstract}

\section{INTRODUCTION}

In conflict situations the decisions are influenced by personality, mood, cultural background as well as by perceptions. Our aim is to develop paradigms and modeling and simulation methodologies for the conflict management problems. Along this line, we formulated and continue working on multimodels and multisimulations (Ören 2001a, Yilmaz and Ören 2004) as well as on fuzzy agents with dynamic personality (Ören and Ghaseem-Aghaee 2003, Ghaseem-Aghaee and Ören 2003). Multimodels allow encapsulation of several aspects of reality that some or all of which may exist under present or emerging conditions. Multisimulations can be used to explore branching simulation studies to explore the consequences of several emerging and sometimes contradictory situations. Agents with dynamic personality reflect the state-of-the-art knowledge on personality theories and allow dynamic update of the personality of a fuzzy agent. There are already several agent simulation studies to take into account the effect of personality in a simulation study.

In this article, we present a systematic and comprehensive view of input with a special emphasis on perception, treat anticipation as a type of perception, discuss how anticipation can be included in a simulation study, and elaborate on other aspects of perceptions in simulation studies especially in conflict situations.
Levent Yilmaz

M\&SNet: Auburn Modeling \& Simulation Laboratory Department of Computer Science and Engineering Auburn University Auburn, AL 36849, U.S.A.

\section{TYPES OF INPUTS FOR SOFTWARE MODULES}

In a typical computation, it is taken for granted that a computational unit (a software module, including a software agent) will have inputs and outputs. Inputs to a computational unit can be generated outside of the unit (exogenous input) or generated inside the unit (endogenous input) (Ören 2001b).

As seen in Table 1, externally generated inputs are two types: passively accepted (or imposed or forced inputs) and actively perceived inputs (or perceived inputs).

Table 1: Types of Exogenous Inputs

\begin{tabular}{|l|l|}
\hline \multicolumn{1}{|c|}{ Mode of Input } & \multicolumn{1}{c|}{ Type of Input } \\
\hline $\begin{array}{l}\text { Passive accep- } \\
\text { tance of } \\
\text { exogenous input } \\
\text { (imposed or } \\
\text { forced input) }\end{array}$ & $\begin{array}{l}\text { Types of access to input: coupling, ar- } \\
\text { gument passing, knowledge in a common } \\
\text { area, message passing, broadcasting, ... }\end{array}$ \\
$\begin{array}{l}\text { Nature of input: } \\
\text { - Data, facts } \\
\text { - Forced events } \\
\text { - Sensation (converted sensory data: } \\
\text { from analog to digital } \\
\text { single or multi sensor - sensor fusion) } \\
\text { - External goals (imposed goals) }\end{array}$ \\
\hline $\begin{array}{l}\text { Active percep- } \\
\text { tion of exogenous } \\
\text { input } \\
\text { (perceived input) } \\
\text { and selected events) (possibly antici- } \\
\text { pated) }\end{array}$ \\
$\begin{array}{l}\text {-- includes: decoding, selection } \\
\text { (filtering), recognition, regulation } \\
\text { - Perceived goals } \\
\text { - Evaluated inputs } \\
\text {-- evaluation of inputs (acceptability) } \\
\text {-- evaluation of source(s) of inputs } \\
\text { (reliability, credibility) }\end{array}$ \\
\hline
\end{tabular}

Conventional inputs to computing units are provided by coupling, several types of argument passing, knowledge in a common area (including blackboarding in artificial intelligence), message passing, and broadcasting. All of them 
are "forced inputs" to the computing unit, i.e., the unit does not need to monitor or detect them. They are readily available. Passive inputs can be data, facts, forced events, sensation, and external goals imposed to a unit.

Actively perceived exogenous inputs consist of perceptions (interpreted sensory data and selected events), perceived goals, and inputs evaluated with respect to acceptability, as well as inputs whose sources are evaluated with respect to reliability and credibility.

Endogenous inputs are shown in Table 2. An intelligent system can monitor itself and can make deductions based on the observed internal facts, or events; or based on the lack of them. The result of introspection can then become internally generated (endogenous) perceived input. Generation of endogenous input can be done by anticipation of facts or events, as well as deliberation of past facts and/or events. Endogenous inputs can be internally generated questions, hypotheses, or goals.

Table 2: Types of Endogenous Inputs

\begin{tabular}{|l|l|}
\hline \multicolumn{1}{|c|}{ Mode of Input } & \multicolumn{1}{c|}{ Type of Input } \\
\hline $\begin{array}{l}\text { Active percep- } \\
\text { tion of endoge- } \\
\text { nous input }\end{array}$ & $\begin{array}{l}\text { - Introspection (perceived internal facts, } \\
\text { events; or realization of lack of them) }\end{array}$ \\
\hline $\begin{array}{l}\text { Generation of } \\
\text { endogenous in- } \\
\text { put }\end{array}$ & $\begin{array}{l}\text { - Anticipated facts and/or events } \\
\text { (anticipatory systems) } \\
\text { - Deliberation of past facts and/or events } \\
\text { (deliberative systems) }\end{array}$ \\
\hline $\begin{array}{l}\text { Types of en- } \\
\text { dogenous input }\end{array}$ & $\begin{array}{l}\text { - Internally generated questions } \\
\text { - Internally generated hypotheses by: } \\
\text {-- Expectation-driven reasoning } \\
\text { (Forward reasoning, or } \\
\text { (Bottom up reasoning, or } \\
\text { (Data-driven reasoning) } \\
\text {-- Model-driven reasoning } \\
\text { - Internal goals } \\
\text { (internally generated goals) }\end{array}$ \\
\hline
\end{tabular}

\section{ANTICIPATION AND ANTICIPATORY SYSTEMS}

Anticipation is an important characteristic of intelligence. Pro-active behavior requires anticipatory abilities. Without anticipation a system can only be reactive; a dead frog can also be reactive. A seminal work on anticipatory systems is the one written by Rosen (1985). A brief introduction to and serious concerns about anticipation follows:

"Strictly speaking, an anticipatory system is one in which present change of state depends upon future circumstances, rather than merely on the present or past. As such, anticipation has routinely been excluded from any kind of systematic study, on the grounds that it violates the causal foundation on which all of theoretical science must rest, and on the grounds that it introduces a telic element which is scientifically unacceptable. Nevertheless, biology is replete with situations in which organisms can generate and maintain internal predictive models of themselves and their environments, and utilize the predictions of these models about the future for purpose of control in the present. Many of the unique properties of organisms can really be understood only if these internal models are taken into account. Thus, the concept of a system with an internal predictive model seemed to offer a way to study anticipatory systems in a scientifically rigorous way" (Rosen 1985, from forward).

Dubois started a series of conferences on anticipatory systems (Dubois 1998, 2000). A systematic review of 12 definitions of anticipation is available from BISC-SIG with the following warning: "The following 12 definitions, or descriptions, of anticipation should be understood as working hypotheses. It is hoped and expected that the knowledge community of those interested in anticipation will eventually refine these definitions and suggest new ones in order to facilitate a better understanding of what anticipation is and its importance for the survival of living systems" (BISC-SIG 2004). An important aspect from the point of view of BISC-SIG is the emphasis on soft computing requirements in anticipation.

\section{PERCEPTION}

The way we perceive reality affects our feelings, decisions, and actions. Since Plato's allegory of the cave that he explained in Book 7 of the Republic, it is well known that perception is very important (Bloom 1968). Wikipedia encyclopedia explains philosophy of perception as follows:

"The philosophy of perception concerns how mental processes and symbols depend on the world internal and external to the perceiver. Our perception of the external world begins with the senses, which lead us to generate empirical concepts representing the world around us, within a mental framework relating new concepts to preexisting ones. Because perception leads to an individual's impression of the world, its study may be important for those interested in better understanding communication, self, id, ego -even reality" (Wikipedia-Phi-per 2004).

There are two types of perception, i.e., external and internal perceptions. Philosophy of perception is concerned with external or sensory perception. 
- "External or sensory perception, tells us about the world outside our bodies. Using our senses of sight, hearing, touch, smell, and taste, we discover colors, sounds, textures, etc. of the world at large.

- Internal perception tells us what's going on in our bodies. We can sense where our limbs are, whether we're sitting or standing; we can also sense whether we are hungry, or tired, and so forth." (Wikipedia-Phi-per).

Both types of perceptions can involve thought processes. Introspection is the detailed mental self-examination of feelings, thoughts, and motives.

"In psychology and the cognitive sciences, perception is the process of acquiring, interpreting, selecting, and organizing sensory information. Methods of studying perception range from essentially biological or physiological approaches, through psy-chological approaches to the often abstract 'thought-experiments' of mental philosophy" (Wikipedia-Per).

\subsection{A Categorization of Perception}

A categorization of perception is given in Table 3. Perception of an entity at a time $t$ gives an image of it at that time. At time t, we can refer to the perception as the current perception (or current image), if there is only one perception. However, at a time $t$, based on the perspective, there may be different interpretations of an entity, hence several perceptions. From now on, for the sake of simplicity, unless it is specified otherwise, current perception (or current image) is considered to be unique.

Table 3: Categories of Perception

\begin{tabular}{|c|c|c|}
\hline & \multicolumn{2}{|c|}{ Current images of } \\
\hline & $\begin{array}{c}\text { Past or current } \\
\text { state }\end{array}$ & Future state \\
\hline $\begin{array}{l}\text { others } \\
\text { (people } \\
\text { and/or } \\
\text { events) }\end{array}$ & $\begin{array}{l}\text { Perceived image } \\
\text { of others and } \\
\text { events }\end{array}$ & $\begin{array}{l}\text { Behavioral anticipation of } \\
\text { others and events }\end{array}$ \\
\hline $\begin{array}{l}\text { self (deci- } \\
\text { sion } \\
\text { maker(s), } \\
\text { supporters, } \\
\text { followers; } \\
\text { and/or } \\
\text { events re- } \\
\text { lated with } \\
\text { one's own } \\
\text { side) }\end{array}$ & $\begin{array}{l}\text { Perceived image } \\
\text { of self and/or } \\
\text { events related } \\
\text { with one's own } \\
\text { side }\end{array}$ & $\begin{array}{l}\text { Behavioral anticipation of } \\
\text { self and/or events related } \\
\text { with one's own side }\end{array}$ \\
\hline
\end{tabular}

Current image can refer to external perceptions; hence it can be about others (people, groups, nations, events, facts, etc.). When current image refers to internal perceptions, then it is about self (or own group of decision makers, supporters, followers; and/or events related with one's own side.)

Current image may refer to past, current, or future states. There can be several current images, at different times $t_{i}, i=1,2,3, \ldots, \mathrm{n}$; until future becomes current. This is similar to for example, seven day meteorological forecasts. At each day, there can be a forecast of a certain day until that day. And due to the variability of meteorological conditions, the forecasts may be different. When that specific day occurs, what we experience is the current image of the current state. If we are interested to interpret past events, current image(s) of a certain past may be defined. However, there can be several images of a certain past based on the points of views of the people involved. Current images of (past, current, or future states) can reflect possibly different interpretations of the current perceptions. Hence, especially in a conflict situation, the opponents may even have antagonistic interpretations of the same situation. Furthermore, emotions such as anger affect the disposition of the decision makers.

\subsection{A Paradigm Shift: Anticipation as Perception}

An anticipatory system is a system whose next state depends on its current state as well as the current image(s) of its future state(s). This definition is a radical departure from the original definition given by Rosen (1985): “An anticipatory system is a system determined by a future state. The cause lies in the future." However, our definition is in line with the following definition also given by Rosen: "An anticipatory system is a system containing a predictive model of itself and/or of its environment that allows it to change state at an instant in accord with the model's predictions pertaining to a later instant" (Rosen 1985). However, we would like to stress the distinction on dependency of next states on current image(s) of future state(s) rather than the future values of the states.

Perception, as a concept, encompasses anticipation. For the sake of uniformity in treating current image(s) of past, current, and future states of others or self, it may be advantageous to refer to anticipation as special case of perception. In this way, images of past, present, or future can be used in a similar way especially by agents for which it is customary to have some type of perception.

\section{BEHAVIORALLY ANTICIPATORY SIMULATION}

Systems whose next state depend on current image(s) of future state -instead of future values of the states- can be properly named behaviorally anticipatory systems. Behaviorally anticipatory systems are consistent with principle of 
causality where cause has to precede effect. Simulations where behaviorally anticipatory system models are used can be named as behaviorally anticipatory simulations.

\subsection{Behaviorally Anticipatory Agents}

Perception ability is a required characteristic of agents. Hence, they can be designed to perceive current state of self and others. They can also be designed to create current image(s) of future state(s).

Perception requires mechanisms that enable interpretive capabilities. Perception invariably involves sensory qualities, and introspection entails accessing sensations and perceptions the agent would introspect. Perceptions are derived as a result of interpretation of sensory inputs within the context of the current world and agent's self model. The prototype inference, orientation accounting, and situational classification mechanisms (Sallach 2003) could be used to realize the interpretation capabilities of an agent. The interpretation process results in perceptions. An anticipatory agent needs to deliberate upon perceptions through introspection and reflection to anticipate.

Introspection is deliberate and attentive because higher-order intentional states are themselves attentive and deliberate. An introspective agent should have access mechanisms to its internal representation, operations, behavioral potentials, and beliefs about its context. Reflection uses the introspective mechanisms to deliberate its situation in relation to the embedding environmental context. These features collectively result in anticipation capabilities that orient and situate an agent for accurate future projections. Figure 1 presents interpretation and introspection as critical components within the micro-architecture of an anticipatory agent.

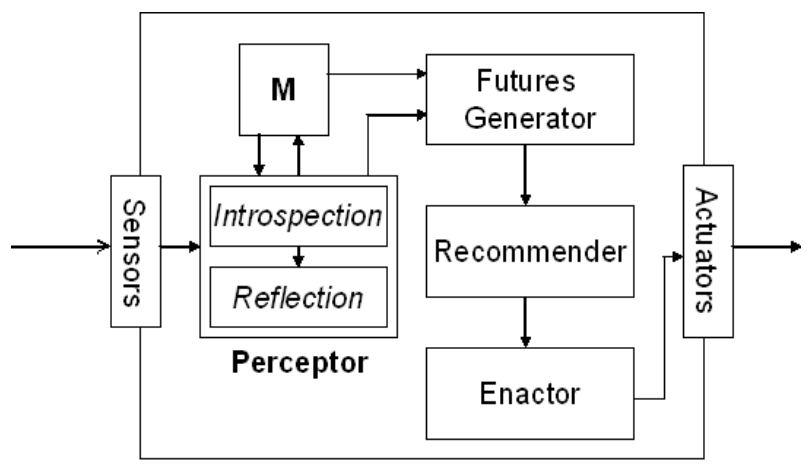

Figure 1: Basic Components for Anticipatory Agents

A computationally anticipatory agent needs to incorporate interpretation facilities as a precursor to (1) comprehend and draw accurate inferences about the world, (2) have social pragmatism by considering the likely responses of others in its context in response to a communication or act, and (3) have situational definition (Sallach 2003) as a direct input to action recommendation. A categorization of understanding can be used to systematize the types of understanding to be implemented in agents (Ören 2000).

An anticipatory agent uses a domain model $\mathbf{M}$, as the internal representation of the environment and agent's self in order to project to the future. The model and the anticipation that results from the introspection and reflection processes are used to derive a number of realities by the futures generator. The generator is a function that maps environmental parameters and past vector of states onto a set of future states of the environment. Naturally, an inductive process would be used to realize the function, as the generation of future plausible realities (environmental contexts) results in a set of new models that vary from each other based on assumptions on different plausible events or possible interactions between the environment and the agent itself. This perspective is consistent with the definition of anticipation process that is given in (BISC-SIG 2004). According to the definition, anticipation (1) is a realization within the domain of possibilities and/or (2) involves the generation of a multitude of dynamic models and the resolution of their conflict. As such, the recommender subsystem is responsible for evaluating alternative anticipated models and to decide on choosing a specific strategy based on the goals and motivations of the agent. Next, a recommender system should select a desirable future state upon which the agent would make decisions and react using its enactor component.

Developing anticipatory agents with runtime recommenders is difficult, because interpretation of emergent conditions requires mining the state of the simulation to recognize situations within the domain theory (schema) of an application. That is plausible and desirable future states need to be qualified based on the motives and goals of the agents. Learning takes place as recommendations are made. Adaptive models that assume certain discernible patterns in the recommendations may be used to discover situations and associated relevant models so as to reinforce qualification of specific future states based on previous experience. Various domain specific representational issues and inadequacies make this very difficult for particular applications. One form of representational inadequacy pertains to intrinsic difficulty of determining (and utilizing) the features that are potentially relevant for model selection. Another form of representational inadequacy involves on deciding the right level of detail.

A major difference between traditional deliberative agents and an anticipatory agent is that an anticipatory agent makes guesses about the future state of the environment to guide its behavior, whereas conventional deliberative agents make their decisions based on the observed conditions within the current context.

\subsection{Agents in Behaviorally Anticipatory Simulation}

Anticipation is a pervasive factor that surrounds many realistic and interesting intelligent processes embedded in social 
systems, as well as symbolic systems. Stock markets, for instance, are driven by perception and anticipation. Motivation mechanisms underling art and science are rooted at anticipation of a desirable result. There are practical applications of anticipation, where agents play a critical role. Anticipatory scheduling is suggested by (Iyer and Druschel 2001) as a disk scheduling framework to overcome deceptive idleness in synchronous I/O. Conventional agents without the types of advanced perception capabilities as promoted in this article can be used as enablers within simulations of suchanticipatory systems.

The following formal requirements stated by (Rosen 1985 ) with regard to anticipation suggest a potential role of contemporary research in agent theory as an enabler paradigm for anticipatory systems. According to his formulation, an anticipatory system should contain a model of the environmental context that it interacts with. This model needs to be predictive and its present state should provide information that facilitates derivation of future states of the environment. As such, anticipation requires observing and collecting measurements of interest and making inferences about plausible future states. Within real-time anticipatory systems, agents can couple data collection with real-time events (socio-political, economics, environment etc.). They can bridge the boundaries of the temporal and spatial distortions that will be exhibited by for example, terrorist activities to foresee the consequences of actions within conflicts. They can also reason from observed events, inquire about information, share assertions, generate hypotheses, check plausibility and establish confidence, adapt, and rationalize from present data and generalize disparate elements to provide incremental improvements in confidence estimates about future projections.

\subsection{Other Aspects of Perception in Simulation Studies}

Perceptions -including anticipations- are subjective and are prone to biases and influences. Some biases may stem from lack of relevant knowledge, others may be induced by others by influencing decisions. We need the mechanisms -albeit fuzzy - to simulate them properly. Motivation and halo effect are positive biases; however halo effect may also be deceptive. Bases for persuasion (i.e., reciprocation, consistency, social validation, liking, authority, and scarcity) are well explained by (Cialdini 2004). Unsymmetric information, misinformation, and disinformation are part of techniques used to influence the perceptions.

\subsection{Relationships of Perceptions and Multimodels and Multisimulations}

Political, economic, military as well as terrorist conflicts are the most destructive elements of the modern world. Proper methodologies are needed to conceive realistic models of complex conflict systems, the behavioral trajec- tory of which is never fixed due to uncertainty in various phases of the problem. New simulation methodologies can help us perceive, conceive, and foresee conflicting situations to ideally avoid them and -if they are inevitable- to resolve them. Multimodel and multisimulation formalisms are suggested (Ören 2001a, Yilmaz and Ören 2004) as a promising approach to deal with uncertainty, as well as multi-phased problems. Such problems include uncertainty, as well as the cases where the nature of the problem changes as the simulation unfolds, and information about the performance is acquired during the actual simulation rather than before. In conventional simulation the results of a model run are viewed as a prediction of what we would expect to occur, which is contradictory to inherent uncertainty in human and social conflicts.

As articulated in Yilmaz and Ören (2004) the major issue underlying multisimulation is the need for run-time switching of models based on interpretation of emergent, potentially unforeseen, conditions to facilitate dynamic run-time simulation composition and simultaneous experimentation with multiple plausible models. Online model recommenders augmented with anticipatory simulation capabilities and future generators will have capability to interface with the simulation kernel and the underlying operating environment to make recommendations as needed to explore the solution space. Exploration of the problem state space using feasible sequence or stages of models would enable experimentation with alternative realities, potentially, at different levels of resolution. Detecting relevant and significant situations in a problem domain would require interpretation capabilities regarding emergent conditions and cause of observed effects. Observed effects need to be attributed to certain causes within the domain theory of the problem at hand. Such causes need to be appraised against the problem solving goals and preferences to make recommendations for further, potentially simultaneous, exploration of different realities. While this scheme can be characterized as forward multisimulation, it is also worthwhile to examine the possibility of backtracking and replaying situated simulation histories with altered conditions, as well as futures generated before exploring alternative realities. Anticipatory simulation concepts suggest a strategy for the realization of multisimulation.

\section{CONCLUSIONS}

Behavioral anticipation is compatible with other types of perceptions and is a desirable characteristics to model and simulate pro-active behavior. In conflict management simulations behavioral anticipation needs to be taken into account.

\section{REFERENCES}

BISC-SIG (2004). Special Interest Group in Anticipa tory Systems. BISC (Berkeley Initiative in Soft Comput- 
ing) Available online via <http://www . anticiption. info/> (accessed on April 9, 2004).

Bloom, A. (1968). "The Republic of Plato" translated with notes and an interpretive essay. Basic Books Inc., New York.

Cialdini, R.B. (2004). The Science of Persuasion. Scientific American - Mind, Special Edition, 70-77.

Dubois, D. M. (1998). Computing Anticipatory Systems with Incursion and Hyperincursion. In D. M. Dubois, Computing Anticipatory Systems: CASYS'97, AIP Proceedings Vol. 437, pp. 3-29. American Institute of Physics, Woodbury, New York.

Dubois, D. M. (2000). Review of Incursive, Hyperincursive and Anticipatory Systems - Foundation of Anticipation in Electromagnetism. In D. M. Dubois, Computing Anticipatory Systems CASYS'99. AIP Proceedings Vol. 517, pp. 3-30. American Institute of Physics, Melville, NY.

Ghasem-Aghaee, N. and Ören, T.I. (2003). Towards Fuzzy Agents with Dynamic Personality for Human Behavior Simulation. Proceedings of the 2003 Summer Computer Simulation Conference, Montreal, PQ, Canada, pp. 3-10.

Iyer S. and Druschel P. (2001). Anticipatory Scheduling: A Disk Scheduling Framework to Overcome Deceptive Idleness in Synchronous I/O. In Proceedings of the $18^{\text {th }}$ ACM Symposium on Operating Systems Principles.

Ören, T.I. (2000 - Invited Opening Paper). Understanding: A Taxonomy and Performance Factors. Melville, In: D. Thiel Proceedings of FOODSIM'2000, Nantes, France. SCS, San Diego, CA, pp. 3-10. Available online via <http://www.site.uottawa.ca/ oren/pubs/D75-U-Nantes.pdf> (accessed on April 9, 2004).

Ören T.I. (2001a - Invited contribution). Towards a Modelling Formalism for Conflict Management. In: Discrete Event Modeling and Simulation: A Tapestry of Systems and AI-based Theories and Methodologies, H.S. Sarjoughian and F.E. Cellier (eds.), SpringerVerlag, New York, pp. 93-106.

Ören, T.I. (2001b - Invited Paper). Software Agents for Experimental Design in Advanced Simulation Environments. In: S.M. Ermakov, Yu.N. Kashtanov, and V. Melas (eds.) Proc. of the 4th St. Petersburg Workshop on Simulation, pp. 89-95. Available online via <http://www.site.uottawa.ca/ oren/ pubs/D79-StPetersburg.pdf > (accessed on April 9, 2004).

Ören, T.I. and Ghasem-Aghaee, N. (2003). Personality Representation Processable in Fuzzy Logic for Human Behavior Simulation, Proceedings of the 2003 Summer Computer Simulation Conference, Montreal, PQ, Canada, pp. 11-18.

Rosen R. (1985) Anticipatory Systems - Philosophical, Mathematical and Methodological Foundations. Pergamon Press, New York. Available online via
$<$ http: //www . panmere.com/rosen/detas. htm $>$ (accessed on April 9, 2004).

Sallach D. (2003). Interpretive Agents. In Proceedings of the Agent2003: Challenges in Social Simulation Conference. University of Chicago..

Wikipedia: (Per) (2004) Perception. Available online via <http://en.wikipedia.org/wiki/ Perception> (accessed on April 9, 2004).

Wikipedia: (Phi-Per) (2004) Philosophy of Perception. Available online via <http: //en.wikipedia. org/wiki/Philosophy_of_perception> (accessed on April 9, 2004).

Yilmaz, L. and T. Ören (2004). Dynamic Model Updating in Simulation with Multimodels: A Taxonomy and a Generic Agent-Based Architecture. Proc. of the Summer Computer Simulation Conference, 2004, pp. 3-8.

\section{AUTHOR BIOGRAPHIES}

TUNCER ÖREN is a professor emeritus of computer science at the School of Information Technology and Engineering of the University of Ottawa (Canada). He has contributed to: (1) the advancement of modeling and simulation methodologies; (2) the synergy of: simulation, system theories, cybernetics, artificial intelligence, and software engineering; (3) the reliability issues in modeling and simulation; and (4) ethics in simulation. Currently he is a member of the Board of Directors, AVP for Ethics, and Founding Director of the McLeod Modeling and Simulation Network of the Society for Modeling and Simulation International. Over 330 publications; some translated in Chinese and German. Contributions in over 300 conferences and seminars held in 28 countries. URL: <http: //www.site. uottawa.ca/ oren/>

LEVENT YILMAZ is Assistant Professor of Computer Science and Engineering in the College of Engineering at Auburn University and co-founder of the Auburn Modeling and Simulation Laboratory of the M\&SNet. His research interests are (1) advancing the theory and methodology of modeling and simulation to explore understanding and managing conflicts, (2) agent-directed simulation, and (3) reuse. $\mathrm{He}$ has published in the areas of agent-directed simulation, conflict modeling and simulation, model VV\&T, and reuse. He currently serves as the associate chair for the Theory and Methodology Council of the Society for Computer Simulation International. He is a member of ACM, IEEE Computer Society, Society for Computer Simulation International, and Upsilon Pi Epsilon. URL: $<$ http://www.eng.auburn.edu/ yilmaz> 